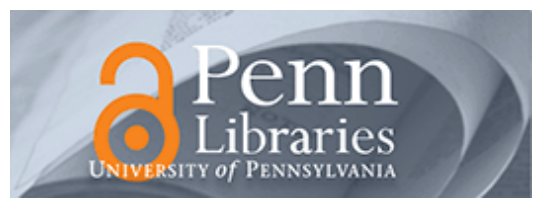

University of Pennsylvania

ScholarlyCommons

\title{
Safeguarding Play in Virtual Worlds: Designs and Perspectives on Tween Player Participation in Community Management
}

\author{
Yasmin B. Kafal \\ University of Pennsylvania, kafal@gse.upenn.edu \\ Kristin A. Searle \\ University of Pennsylvania, searle@dolphin.upenn.edu
}

Follow this and additional works at: https://repository.upenn.edu/gse_pubs

Part of the Education Commons

\section{Recommended Citation}

Kafal, Y. B., \& Searle, K. A. (2010). Safeguarding Play in Virtual Worlds: Designs and Perspectives on Tween Player Participation in Community Management. Retrieved from https://repository.upenn.edu/ gse_pubs/223

Suggested Citation:

Kafal, Y.B. and Searle, K.A. (2010). Safeguarding Play in Virtual Worlds: Designs and Perspectives on Tween Player Participation in Community Management. International Journal of Learning and Media. Vol. 2(4). pp. 31-42.

\section{(c) 2010 MIT Press \\ http://www.mitpressjournals.org/loi/ijlm}

This paper is posted at ScholarlyCommons. https://repository.upenn.edu/gse_pubs/223

For more information, please contact repository@pobox.upenn.edu. 


\title{
Safeguarding Play in Virtual Worlds: Designs and Perspectives on Tween Player Participation in Community Management
}

\author{
Abstract \\ Managing problematic interactions in online communities has been a challenge since the days of early \\ text-based, multi-user environments. Research in this area has mostly focused on adults and older teens. \\ In this article, we examine the interactions and commentaries of tween players in Whyville.net, a virtual \\ world with (at the time of the study) more than 1.5 million registered players ages 8-16. To understand \\ how tween players define problematic behavior and what they observe in their own community, we draw \\ from an archive of online postings to Whyville's newspaper. The postings cover the period from 2000 to \\ 2009 and consist almost entirely of player-generated content. Complementing these tween writings are \\ observations of an after school gaming club in which, over a period of three months, about 20 youth \\ players ages 9-12 met almost daily to play for an hour on Whyville.net. We highlight one particular \\ incident observed in the gaming club because it illustrates how club members dealt with problematic \\ behavior experienced online. Finally, we address the challenges and opportunities that tween player \\ participation in community management presents for managing online behavior and player safety.

\section{Disciplines} \\ Education

\section{Comments} \\ Suggested Citation: \\ Kafal, Y.B. and Searle, K.A. (2010). Safeguarding Play in Virtual Worlds: Designs and Perspectives on \\ Tween Player Participation in Community Management. International Journal of Learning and Media. Vol. \\ 2(4). pp. 31-42.

\section{(c) 2010 MIT Press} \\ http://www.mitpressjournals.org/loi/ijlm
}




\section{Safeguarding Play in Virtual Worlds: Designs and Perspectives on Tween Player Participation in Community Management}

Yasmin B. Kafai

University of Pennsylvania

Graduate School of Education

kafai@upenn.edu

\section{Kristin A. Searle}

University of Pennsylvania

Graduate School of Education

searle@dolphin.upenn.edu

Keywords

tweens

virtual worlds

community management

Visit IJLM.net

doi:10.1162/ijlm_a_00053

(C) 2011 Massachusetts Institute of Technology

Published under Creative Commons Attribution-Noncommercial-No

Derivative Works 3.0 Unported license

Volume 2, Number 4

\section{Abstract}

Managing problematic interactions in online communities has been a challenge since the days of early text-based, multi-user environments. Research in this area has mostly focused on adults and older teens. In this article, we examine the interactions and commentaries of tween players in Whyville.net, a virtual world with (at the time of the study) more than 1.5 million registered players ages $8-16$. To understand how tween players define problematic behavior and what they observe in their own community, we draw from an archive of online postings to Whyville's newspaper. The postings cover the period from 2000 to 2009 and consist almost entirely of player-generated content. Complementing these tween writings are observations of an after school gaming club in which, over a period of three months, about 20 youth players ages 9-12 met almost daily to play for an hour on Whyville.net. We highlight one particular incident observed in the gaming club because it illustrates how club members dealt with problematic behavior experienced online. Finally, we address the challenges and opportunities that tween player participation in community management presents for managing online behavior and player safety. 


\section{Introduction}

Managing problematic interactions in online communities has been a challenge since the days of early text-based, multi-user environments, also called multi-user dungeons (or dimensions or domains; all three variants commonly shortened to the acronym MUD) (Dibbell 1998). Cheating, for example, is considered a common aspect of participation in gaming communities (Salen and Zimmerman 2004; Consalvo 2007; Steinkuehler 2007; Boellstorff 2008). However, research on deviance in online communities has tended to focus on adults and older teens (Fields and Kafai 2009). As millions of younger children and tweens join virtual worlds and multiplayer gaming communities, this issue demands increased attention. Understandably, parents want their children to be safe while playing at home, and educators have a responsibility for the content students encounter while learning online at school, as well as for their online safety in general. In addition, media outcry has heightened awareness of what younger children and tweens might encounter online-from explicit language (Subrahmanyam, Smahel, and Greenfield 2006) to cyberbullying to sexual predators (Cassell and Cramer 2008). In response to these concerns, a number of measures have been developed to protect children and youth online. These include legal and technical solutions and, to a lesser extent, social solutions - the latter are the focus of this paper.

Most of the solutions employed by Web service providers to manage problematic behavior are of a legal or technical nature (Federation of American Scientists 2009). At a basic level, the federal Children's Online Privacy Protection Act (COPPA) legally mandates that hosts of online services and commercial websites adhere to a series of privacy protection and safety measures when collecting information from individuals under the age of 13 . In addition, most online game companies make players sign an enduser agreement when they join or log in to a site. The agreement defines the site's or game's parameters of appropriate behavior. Technical security measures such as chat filters limit the use of problematic language, and many sites employ adult moderators to keep behavior in check (Subrahmanyam, Smahel, and Greenfield 2006). Concerned parents use programs like Net Nanny to regulate children's movements on the Web or simply keep their children offline by prohibiting access to the Internet.
Much less prominent are social approaches to community management. These involve players monitoring interactions with their peers (Keith and Martin 2005). Recently the demand for more player participation has increased in response to discussions of ownership and governance within adult gaming communities (e.g., Taylor 2006), but the topic is just as relevant for youth communities. Assigning more responsibilities to players is an equally important step for younger players who are transitioning from childhood into adolescence. Tweens, youth between the ages 10 and 13, are a particularly relevant group. They still need protection because they are legally minors, but they also need space to develop skills of their own in preparation for more independent ventures. To assess the feasibility of involving young players in community management, we must examine more closely how tween players define and respond to problematic behavior.

In this paper, we take a first step toward a better understanding of how player participation in community management can be configured in virtual worlds for youth. We examined the interactions and commentaries of tween players in Whyville.net, a virtual world that had more than 1.5 million registered players ages 8-16 at the time of the study (as of 2010 that figure had grown to more than 5 million players). To understand how tween players define problematic behavior and what they observe in their own community, we drew from an archive of online postings to Whyville's newspaper. The postings cover the period from 2000 to 2009 and consist almost entirely of player-generated content. Complementing these tween writings are observations of an after school gaming club in which, over a period of three months, about 20 youth players ages 9-12 met almost daily to play for an hour on Whyville.net. We highlight one particular incident observed in the gaming club because it illustrates how club members dealt with problematic behavior experienced online. Finally, we address the challenges and opportunities of tween player participation in the management of online behavior and player safety (Greenfield 2004).

\section{Background}

As early as 1994 a panel of virtual community designers at the Computer Human Interaction (CHI) conference in Boston directed attention to "the unfortunate fact of life that where there are multi-user computer 
systems, there will be antisocial behavior" (Bruckman et al. 1994). The text-based MUDS and virtual communities of the 1990s-LambdaMoo, MediaMoo, The Well-were precursors of today's 2D and 3D massively multiplayer online role-playing games (MMORPGs) and virtual worlds. Now, as then, deviance in the form of cheating is considered a common aspect of game play (Gee 2003; Salen and Zimmerman 2004; Consalvo 2007; Steinkuehler 2007; Boellstorff 2008). Some researchers (e.g., Gee 2003; Consalvo 2007) view cheat sites as part of the cultural fabric of a gaming community and see participation in these sites as central to being an active community member. In response, the companies behind virtual communities (or the hosts of those communities) have operated virtual worlds with varying degrees of freedom. For example, "[s]ome MUDs are operated with a very strict top-down approach in which the wizards or administrators maintain a strong vision of what the world should be and set policy and program accordingly. In other spaces, users are allowed more freedom to create and build, or develop story lines" (Taylor 2006, p. 27).

As players increasingly contribute content to virtual worlds and games, the focus has shifted from community management to self-governance (Taylor 2006; 2009). The new focus on player participation in the governance of adult gaming communities provides the context for our examination of young players' potential role in community management. Millions of tweens and teens have joined social networking sites and virtual worlds such as Habbo Hotel, Webkinz, and Neopets. Participation on such sites often exceeds that on many adult gaming communities. Unlike virtual communities composed mainly of adults and older teenagers, virtual communities targeting tweens and younger kids are faced with a particular challenge in creating a safe yet relatively independent space for play, exploration, and learning. Early adolescents present a particular challenge to site designers and managers because they are simultaneously more sophisticated than children and less sophisticated than adults. Site designers and managers need to grant tweens some decision-making authority while also maintaining an environment of protective regulation. As Greenfield (2004) observes, adolescents in unregulated online communities may be confronted with events they are not prepared to handle and which could have negative developmental consequences. At the same time, however, Greenfield acknowledges that the relative level of supervision, or lack thereof, offered by a site's host is only part of the problem. The various cultures that exist in online spaces populated primarily by adolescents are also coconstructed by adolescents to some degree. Player culture is a part of the problem. Therefore, making it part of an effective system of community governance seems logical.

In addition, the idea of creating and maintaining safe play spaces is itself problematic. Historically, children's play has always had deviant and aggressive elements (Thorne 1993/1998; Pellegrini 1995; Rotundo 1998). Like their adult counterparts, young players use cheat codes and cheat sites (among other problematic behaviors) (Fields and Kafai 2008; Stevens, Satwicz, and McCarthy 2008). They have also become embroiled in some of the same debates occurring in adult-oriented virtual communities. Player codes of conduct in and of themselves are not enough to discourage problematic behavior, and technical constraints such as word filters are only initially effective; players soon figure out ways around them. The recent demand for increased player participation in the governance of online communities suggests an alternative approach that places more responsibility on players for managing their own behavior. In extending these responsibilities to younger players, however, we face additional challenges. Such an approach is at odds with many currently implemented legal, technical, and parental measures, which seem to err on the more restrictive side. Also, educators do not agree on what constitutes appropriate behavior for particular age ranges (see Lubeck 1998). Notions such as "developmentally appropriate" (Greenfield 2004) seem to suggest an agreement on universals, but the great range of socioeconomic, ethnic, and racial backgrounds among tweens leads to great diversity in how they interact. Variation in what parents deem safe and appropriate for their children only adds to the complexity of the challenge.

In order to make an informed decision about the appropriate balance of caretaking and self-governance in virtual worlds populated largely or exclusively by youth, we approached issues of community management from different perspectives. By examining the features of virtual worlds, player perspectives, and interactions among players, we were able to contrast design with actual use. We first reviewed community management features in Whyville and comparable virtual worlds. We then observed tween interactions on Whyville, examining incidents of problematic 
behavior and how players handled such situations. Finally, we considered what tween players wrote about the problematic behavior they experienced or witnessed. To do this, we first analyzed the content of writings posted in the Whyville Times, the weekly online newspaper in Whyville. By combining a content analysis of articles relating to community management issues in The Whyville Times with an analysis of an actual community management event, drawn from chat logs and ethnographic observations in an after school gaming club, we were able to develop a nuanced portrait of what tweens do and say about such incidents.

\section{Contexts, Participants, and Data}

Virtual worlds are designed communities (Bartle 2003) whose hosts choose to include or exclude (to varying degrees) player participation in community management. We reviewed the design features of sites such as Barbie Girls, Club Penguin, and Nicktropolis (renamed and relaunched as The Club in March 2010) (Federation of American Scientists 2009) because they are comparable to Whyville.net in scope and size of player audience. In addition, we reviewed a document on technical security features and community management produced by Numedeon, Inc., the host of Whyville.net.

To understand actual player participation in community management, we drew on participants' activities in an after school gaming club and in the online world. In January 2005, we started an after school gaming club for fourth through sixth graders (ages 9-12) who had signed up to play in Whyville.net (Kafai 2008). The 20 students who joined the club were racially and ethnically diverse and came from a range of socioeconomic backgrounds. All had access to computers at home and in school. The Whyville club met for an hour after school four days a week from January to March, and, though an adult was always present in a supervisory capacity, club members were given no direction as to how to spend their time in Whyville. Members distributed themselves among the club's 10 computers, often sharing or clustering around a computer to observe play in Whyville when something especially interesting was happening on a player's screen. They also wandered around the room and talked among themselves as they played. All real and online names of youth in this paper are pseudonyms.
Static video cameras captured group interactions at computer clusters and rotated from cluster to cluster over the course of the week. Field notes recorded at 15-minute intervals by the supervising adult captured club atmosphere and conversation at large. From January to June 2005, Numedeon's log files captured the online movements (via mouse-clicks and chat interactions) of 595 players, including the students in the after school gaming club (Kafai and Fields, forthcoming; consent to collect and analyze the log file data was obtained from all 595 players and their parents). The ability to retrace participation across multiple locations was essential in helping us understand how club members responded to a real-time community management threat involving one of their peers. This incident was the only one of its kind observed and recorded in the after school club during the period of the study. However, club members might have had experiences with community management challenges while participating in the club that they chose not to make public by telling their peers or sharing with the supervising adult. They might also have dealt with such challenges when playing in Whyville outside of the gaming club.

In order to understand player perspectives on community management, we investigated the archives of Whyville's weekly newspaper. By examining what players wrote in The Whyville Times from 2000 to 2009 , we were better able to understand how Whyvillians see themselves as members of a community and conceptualize their role in maintaining that community as a safe, fun, and educational space. We were also able to chart changes in Whyville.net's community management tools over time, from the early implementation of chat filters to a later (failed) attempt at community policing called the Whyville Safety Patrol. In particular, we were interested in citizens' use of 911 reports and other community policing tools (vaporizing, silencing, and the now defunct Whyville Safety Patrol), as well as their understandings of appropriate punishments for particular transgressions. We searched for articles containing "911 report" (138 articles), "Whyville Patrol" (4 articles), and "harassment" (17 articles). We read all of the articles and developed an inductive coding scheme. We then coded for active citizen participation, bad language, bullying, cheating, community management tools (including 911 reports, how to use, appropriate and inappropriate usage of), cybersex, discrimination (general—e.g., against newer players or less attractive 
community members), hacking, harassment (mild), Internet safety, nudity and gore, racial discrimination, religious discrimination, safety patrol, and sexual harassment. We also noted each article's general stance toward the issue being discussed and whether an editor's note or a comment from City Hall was included. (City Hall is the governing body in Whyville responsible for setting rules and regulations; it is composed of adults who are Numedeon employees and known as "city workers.")

The Whyville Times is player written, but articles are first submitted to the paper's editor, an employee of the company that owns Whyville.net. The editor selects articles for publication. Thus, while a broad range of topics and opinions is covered by The Whyville Times, which often publishes articles representing conflicting viewpoints on the same topic, we cannot assume that the paper is fully representative of Whyvillians' opinions in general because we do not know the full range of criteria that influence the decision to (not) publish a particular article in The Whyville Times. Nonetheless, the editor's presence in "editor's notes" provided us with a perspective on actions initiated by the company to maintain particular standards of behavior within Whyville.

\section{Findings}

The community management structures in Whyville .net establish an environment where tweens can play in a supervised place and begin to take on more responsibility for self-governance. However, design is only one aspect of any virtual environment. How do the citizens of Whyville put the idea of player participation into practice? We examined the design, use, and discussion of community management as young players co-constructed their online lives within this environment (Taylor 2006).

\section{Design of Community Management}

Whyville's design as a virtual community creates certain possibilities for and limitations of player participation in community management. Whyville has a number of technical security measures in place but also employs social solutions that allow tweens to monitor one another's behavior in the community. When players first sign up to become members of the Whyville community, they must get parental permission if they are under age 13, as mandated by COPPA. Parents are encouraged to fax or email a signed permission slip to Numedeon, a parental email is collected at the time of registration, and a confirmation email is sent to notify the parent of the child's participation in Whyville. Players can easily get around these features by lying about their age or simply checking the box that says they and their parents agree to Whyville's privacy policy. A savvy tween could also set up a fake parental email account. Despite (or perhaps because of) these shortcomings, Whyville's legally mandated permission process is only the first step in its safety procedures. Regardless of age, players must take a 20-question, multiple-choice "chat license" test that, if they answer all questions correctly, allows them to chat in Whyville after a waiting period of five days. (Parents of children under the age of 13 may elect to prohibit their child(ren) from chatting in Whyville as part of the consent process.) When they successfully pass the chat license test, players are rewarded with clams (Whyville's virtual currency), which are integral to moving from being a "newbie" to being a more seasoned member of the community because they allow for the purchase of status items, including face parts for one's avatar.

Once players have passed their chat license exam, they are presumed to understand the rules governing behavior in Whyville, as well as the safety measures one should take when hanging out in cyberspace in general. Nonetheless, players still try to type bad words (e.g., \$exy or sessy instead of sexy), so chat filters are in place to keep such words from appearing on the screen. "City workers"-adult employees of Numedeon who wander around Whyville wearing red "CW" caps-also monitor chat to catch offenders whose foul language is missed by the filters. City workers are able to mute, fine, and banish individuals for various chat and behavioral infractions. Finally, individual players have the option of creating lists of words and phrases that they do not want to say (i.e., type) or receive. This is a particularly useful feature for filtering out personal identifying information such as a name or an address. First-time offenders of chat regulations are usually fined (the amount is based on their daily salary) but maintain their chat privileges. Repeat offenders can be punished by losing their chat privileges for varying periods of time (amounts vary with the severity of the offense), how many times the player has been punished before, and how long the user has been a citizen of Whyville. Avatars whose users have been punished for using foul language appear with duct tape across their mouths and are unable to chat. 
In addition to chat filters, a number of tools extend the ability of players to self-govern and determine what they are or are not ready to experience. Of these tools, silencing is the most basic; according to Whyville's safety procedures, it should be used when someone refuses to stop using language that another player finds offensive. By silencing a Whyvillian who is using inappropriate language, a player will no longer "hear" what is being said. Vaporizing goes one step further and makes players invisible to one another; it is best used when someone is being followed or repeatedly annoyed by another player. For extreme cases, players can "911 report" someone. Behaviors that merit 911 reporting include the use of racially or sexually offensive language, engaging in cyber sex, and such classically predatory behaviors as asking for someone's password or other personal information or suggesting a meeting or phone call in real life. In these instances a report is sent to city workers who follow up on the situation and mete out punishment.

Only a few of the sites surveyed by the Federation of American Scientists (2009) gave children and tweens the opportunity to take responsibility for their own behavior. Most sites approached the problem of community management by relying on the topdown solutions offered by COPPA mandates and by employing technical fixes such as chat filters. Among the sites that have tried to shift the focus to player self-governance is Barbie Girls, which gives parents the opportunity to create a "B-Smart" code of conduct for online behavior-essentially a customized, private code established between parent and child. However, the site does not provide mechanisms for children to manage community behavior on their own terms. Club Penguin has a kid-based neighborhood watch that patrols the community. Nickelodeon's The Club (formerly Nicktropolis) allows kids to block chat from other users and provides a safety button with which to report users whose behavior is problematic. The Club's code of conduct explicitly states that hacking the accounts of other users, cheating, and stealing are unacceptable behaviors. At the time of our study, only The Club approached the level of complexity found in Whyville.net's community behavior management tools.

Player Participation in Community Management

We know little about how problematic incidents and players' reactions take place and develop in real time.
What we do know about these kinds of incidents is often through hearsay, whether reported in The Whyville Times or The New York Times. The tweens portrayed in such accounts usually are described as helpless victims or bullies. In contrast, we present a real-time example of how club members and a supervising adult responded to an instance of problematic behavior in Whyville. We describe the collective sense of violation felt by members of the after school gaming club, their use of 911 reporting, and their own efforts at punishing the offensive individual. Our goal is to highlight the complexity inherent in such boundary-testing situations. The incident we observed demonstrates that well-intentioned community policing can sometimes be transformed into behavior that dangerously approaches cyberbullying. The incident we report on is the only one of its kind that we observed and recorded in the club. Lesser incidents such as scamming and verbal insults happen more frequently-nine years' worth of articles published in The Whyville Times makes this apparentand we know that such incidents were not only experienced but also instigated by club members over the course of the study period (see Fields and Kafai, forthcoming).

About six weeks into the after school gaming club, 13 students and one adult clustered around the classroom's 10 computers. Conversation in the club centered on the usual topics: club members compared their salaries (in clams, Whyville's virtual currency), discussed game-playing strategies, and gave one another fashion advice on the styles available at Akbar's Face Mall. Within Whyville, they spent time socializing with their friends, communicating via y-mail (Whyville's email system), "throwing" projectiles at one another, and "teleporting" to various locations, including secret meeting locations such as the planets Mars and Saturn, and the Moon. The conversations taking place in the after school club overlapped one another as the individuals physically present in the room also interacted with one another online.

Ulani and Blake were arranging to chat on Mars when Ulani announced that someone was asking her "something weird" on Saturn. (Mars and Saturn are secret meeting places within Whyville that players can visit only by using the teleport command; see Fields and Kafai 2009). She then clarified, "They're saying, wanna *do it* with me?" which caused another club member, Blake, to run from his chair across the room to the computer where Ulani was playing. The 
adult present was already discussing the situation with Ulani, who announced that she would file a 911 report to document the other individual's inappropriate behavior. Other members of the after school club announced their presence on Saturn or made their way there as the situation gained momentum. Blake, for instance, announced that he wanted to "go to Saturn and see the evidence" and suggested that everyone in the after school club should file a 911 report. With some help from Ulani, Blake teleported to Saturn.

From this moment on, Blake took on a leadership role as a team of players pursued the individual who had asked Ulani if she wanted to "do it." Soon Aidan, Marissa, and Cory were also involved. Aidan announced that he would "get something on this guy" (to which Blake responded, "Yeah, get someone on him") and began to organize the purchase of projectiles to throw at the offensive individual. While Blake, Aidan, and Cory debated what type of projectiles they should purchase, Blake made his way back to the computer he was sharing with Cory and announced, "To the rescue!" to the entire room before focusing his attention on Violet (Ulani's Whyville avatar). In the meantime, Aidan located the offensive individual and announced, "Violet! . . I got him for you." In the club, Ulani thanked Aidan and worried that the offensive individual would retaliate, even as Blake pelted him with more pie projectiles in Whyville. Upon a successful pie throw, Blake did a victory dance in the club and then high-fived several of his friends online and in the club.

As the search effort continued, even more club members became involved in throwing projectiles and name-calling. Once most of the members were on Saturn, they lined up their avatars and counted down before engaging in a collective pie-throwing effort. Then, as they attempted to organize another round of projectile throwing, this time with the addition of "mudballs," the offensive individual fled Saturn. Aidan and Blake immediately volunteered to "go patrol the area." When other members joined in, they split up and visited other public rooms such as Sector Y, the Bazaar, the Beach, the mall, and the food court looking for the offensive individual. Marissa eventually found him at the Beach, but he disappeared into the crowd before the club members were able to take action. They then debated looking him up in city records, filing another 911 report, or going off to play checkers because "the incident" had drawn to a close.
Their time in the after school club was also drawing to a close, and the adult present asked them to log out of Whyville and prepare to go home. As "the incident" and the club session wound down, club members shifted their attention to other topics.

Club members seemed satisfied with their response to the situation-filing official 911 reports and pelting the individual with projectiles. The tweens involved in the incident were not simply passive victims. Most important, Ulani had felt comfortable sharing the incident with the other members of the after school gaming club. All of the club members recognized that a line had been crossed, and they took action to address the problematic behavior Ulani had witnessed. With the support of the supervising adult, they had filed 911 reports. Then, club members had taken matters into their own hands, organizing an effort to track down the offensive individual and pelt him with projectiles.

Community policing actions like the one undertaken by the students in the after school gaming club-however well intentioned the actions might be-reveal some downsides. Most significant, the group's mob-like, bullying behavior brought them close to the territory of cyberbullying. This is a complicated issue for simulations and serious games involving tweens, and it deserves further attention.

Girls and boys in the club participated together in the response to the incident, possibly for different reasons. The girls in the club might have joined the effort simply because they felt a line had been crossed. The boys' motivation was possibly more complex. Blake's call to action ("To the rescue!") is a possible gendered reference to the mission found in many video games; that is, to rescue the princess (Provenzo 1991; Thorne 1993/1998). Perhaps Blake and others positioned themselves as saviors by drawing on their knowledge of video games and transforming the retaliation into a form of situated video game play.

Our observations of "the incident" do not suggest that tweens should be left to deal with such issues on their own. However, given the appropriate supports (a supervising adult in the classroom, parents, a 911 reporting tool), tweens may surprise us with what they are capable of handling.

Players' Perspectives on Community Management In order to better understand how players think about community management issues and the standards of 
appropriate behavior they help to establish, we examined their writings on the topic in The Whyville Times. A search of Whyville Times articles from 2000 to 2009 using the terms "911 report" (138 articles), "harassment" (17 articles), and "safety patrol" (4 articles) yielded 159 articles. Among these, the most common topics are the use of community management tools, including reminders of how and when to use 911 reports (53 percent of articles); hacking and scamming (20 percent); bad language (8 percent); bullying and sexual harassment (4 percent each); and racial discrimination (3 percent). The articles also illustrate developments in the complexity of Whyville's community management tools over time, such as the extension of the 911 reporting tool to Whyville's email system (y-mail) and the introduction of the Whyville Safety Patrol in 2002.

Of all the Whyville Times articles dealing with some form of harassment or discrimination (31 articles), only one claims Whyville is free of harassment ("I love Whyville," May 23, 2002). In contrast, the remaining 30 articles all speak out against harassment, from mean girls to newbie haters to individuals who consistently use "nasty words or racist or sexually offensive language" ("Duct Tape," August 17, 2000). The articles ask individuals who engage in these practices to "please stop," and they remind other community members how they can deal with inappropriate behavior by silencing, vaporizing, or 911 reporting the offensive individual(s). For one article examining the practice of muting or "taping" individuals for using bad language, "Cyranojoe" interviewed city management about the various punishments. He reports that city management emphasized that punishments are "about making it very clear that we don't want inappropriate behavior in Whyville, without overdoing it so much that somebody who makes one or two mistakes will feel like leaving Whyville" ("Duct Tape: Cyranojoe gets the low-down," August $17,2000)$. This is an important observation because it recognizes that tweens are at a developmental stage where boundary testing and exploration of sexuality are expected while reinforcing Whyville's position as a protected space where these kinds of behaviors are considered inappropriate.

In seven articles from the 2000-2009 period, Whyville Times reporters focus on individuals who engage in sexual harassment, defined by one reporter, Sari, as "those people who say nasty sexual things and want to cyber with you" ("Sexual Abuse," August 24,
2000). The reporters, the citizens they interviewed, and the editor all agree that sexual harassment and/or engaging in "cyber sex" are the most inappropriate forms of behavior and should carry the most-severe punishments. In interviews with three Whyvillians, Sari asked whether "the person doing this horrible thing should be put in [Whyville jail] for his/her offense" (if Whyville were to open a jail). All of the interviewees replied in the affirmative. Although players can "911 report" such behavior, the adult city workers are the ones who decide how to handle transgressions.

Other problematic behaviors, such as scamming clams from people through "street selling" (i.e., pretending to sell face parts for clams in unauthorized areas of Whyville) or the (false) promise of a makeover in exchange for the password to your account, are deemed inappropriate by Whyville Times writers but seem to be more tolerated because such schemes can be avoided by following community norms such as trading in designated locations and never giving one's password to others (for more detail, see Fields and Kafai forthcoming). These behaviors are also less connected to development and are more likely to be relatable to things tweens experience in real life-for example, someone cheating on a test in school. Thus, while the same community management tools govern all types of inappropriate behavior, the consensus among Whyville Times writers seems to be that tweens are more ready to handle nonsexual kinds of inappropriate behavior than they are sexually harassing or sexually explicit behavior.

Because Whyvillians cannot avoid being sexually harassed or seeing others engage in sexually explicit behavior simply by following standard Internet safety practices, these behaviors are seen as more egregious community offenses. Tweens may not be as prepared to participate in this area of community management and therefore might need more guidance and support from adults (e.g., parents or Whyville's city workers) and more-knowledgeable peers. The Whyville Times provides a forum for such support by allowing tweens to write about their experiences and by providing (adult) advice in the form of "editor's notes."

Of the seven articles dealing with sexual harassment in The Whyville Times, five chronicle individuals asking, "Will anyone sleep with me?" ("Harassment," May 24, 2001), or personal stories of how uncomfortable it is to be propositioned by someone or to stumble upon others engaging in "cyber sex." For 
instance, in an article entitled "Kissy, Kissy!" Pink Fish recounted,

My last straw was pulled today when I went to tic-tac-toe room \#25 (because \#1 and \#2 were full, most people also try \#25) and in one of the most popular tic-tac-toe rooms I saw/heard this guy and girl pretending to "do it." They were saying what they were doing to each other, really descriptively. The reason their language got through the filter is because they would take letters out in a word so the computer wouldn't think it was bad, but the other person would still know what it meant. ... When I showed up in the middle of their "act" one of them left and the other cursed at me and that got through [the filter], too. Of all places, the tic-tac-toe room ... and in Whyville? Come on! Whyville isn't a dating service or a sick chat place. Please don't use it as one. ("Kissy, Kissy!" October 10, 2003)

Several elements of this passage speak to what is seen as appropriate or inappropriate in Whyville from the players' perspective. First, Pink Fish believes that she should be able to play tic-tac-toe without witnessing other Whyvillians engaging intimately. She makes this belief explicit in her concluding sentiments that sexually explicit language and behavior do not belong in Whyville. That she did not use 911 reporting to report these individuals suggests to some degree a belief in her own ability to handle the situation, because the offensive individuals dispersed upon being caught in the act. The editor, however, took the opportunity to remind Whyvillians about their rights and responsibilities as citizens, including seeking help to deal with challenging situations rather than taking matters into their own hands:

Whyville is a community for kids. Kids are our citizens. And all citizens have a right to hang out, chat, learn and play without being made uncomfortable. ... Any time you see someone saying or doing something like that, please use the 911 Report on them. If it's just cursing, it's probably better if you mute or vaporize them. But if it's sexual behavior or predatory questions, then 911 as soon as you can! The faster you do, the more of your fellow citizens you will be protecting!" ("Editor's Note," October 10, 2003)

In this passage an official, authoritative voice explains what is and is not appropriate in Whyville, with an emphasis on the theory and practice of community policing. The underlying message of this editor's note and others like it (of the five articles we have discussed, four contain editor's notes) is that, although city workers, City Hall, and other representatives of the company that owns Whyville work hard to keep citizens safe through the use of chat filters, community patrols, and other features, citizens also have a responsibility to keep the community safe and appropriate for one another. The editor's note further emphasizes that, although tweens on their own are capable of dealing with minor infractions like the use of offensive language, other infractions require the support of the community's supervising adults. Pink Fish's letter and the editor's note strike a balance between allowing tweens to discuss their experiences and emphasizing that there are times when adults should be called upon for support.

\section{Discussion}

When we talk about community management, we are talking about a continuum - at one extreme are worlds where the power rests firmly with the parent company's master programmers (e.g., a strong adult presence and effective chat filters, as in the case of Whyville); at the other extreme are idealized worlds where everything is player run (i.e., a complete lack of adult presence). The existence of this continuum of social solutions to community management is predicated on the notion that effective legal and technical solutions are already in place to aid players in community management. Along this continuum of social solutions, we have identified various features of community management in virtual worlds and the degree to which they allow players to control and access their in-game environment. Our goal was to examine this space, which is bound by certain legal and developmental constraints because of the ages of most of its players, as it seeks to provide equal room for protection and exploration. However, our observations and analysis of what constitutes appropriate and inappropriate behavior within the particular context of Whyville might not pertain to sites with a different focus or to sites intended for older or younger visitors.

Discussions about community management need to address the definition of problematic behavior itself. On the one hand, many researchers and players consider cheating and scamming to be normal parts of game play_some even see such behaviors as actively 
contributing to the vibrancy of a gaming community (Consalvo 2007; Stevens et al. 2008; Fields and Kafai forthcoming). On the other hand, behavior connected to flirting and dating and/or player safety is not considered a normal part of game play, and efforts are made to protect players from such behaviors. The incident we observed in the after school club provides a vivid illustration of the reactions and responses of tweens facing a serious threat from another member of the virtual world.

Defining "developmentally appropriate" behaviors for tweens-that is, what they should know and do-in a setting such as Whyville is difficult. The term itself assumes a universally agreed-upon definition shared by all stakeholders. However, early childhood specialists have subjected the very concept of developmental appropriateness to widespread critique (e.g., Lubeck 1998), and the same criticisms can be applied to the tween age group; that is, the concept encapsulates a normalistic, singular vision of development rather than acknowledging diversity and plurality. If we move away from the notion that young people within a particular age group have the same or similar needs, then we also need a form of community management that balances protective regulation and a framework allowing for some level of independence and self-governance.

Most tween sites apply technical solutions to the problem of community management (Federation of American Scientists 2009). Few go beyond what is mandated by COPPA, and few emphasize social solutions in which community norms of behavior are established and maintained largely by the players themselves. In Whyville, and by extension in other virtual worlds, player control is defined by an intricate combination of technical and social interactions-chat filters, monitoring by city workers, youth-initiated behavior controls, and consequences for problematic behavior-that work together to maintain a particular community standard for behavior. While transgressions do occur, in Whyville a consensus seems to have emerged concerning which transgressions are typical and can be handled by players on their own and which ones are not. Player-driven management tools are especially key in this regard because they allow players to tailor their experience in Whyville and to engage with topics related to sexuality or racial/ethnic identity (Greenfield 2004). This might make Whyville a relatively safe space in which tweens can practice how to respond in social situations that may be new to them (e.g., being "hit on" or asked out on a date). Although this may be seen as risky (Greenfield 2004), the literature on sex education and older teens suggests, for instance, that making practice decisions and receiving feedback from a more knowledgeable individual can be an important part of making the right decision when it really matters (e.g., Roberto et al. 2007; 2008).

Adult intervention can and should play a role in community management. For instance, all articles in The Whyville Times are player generated and then screened for content and edited by an adult employee of the company that owns Whyville. In spite of this adult intervention, the articles reflect concerns shared by the larger community because the postings are directed to all, invite comments, and are part of a permanent record. The fact that the adult editor of The Whyville Times publishes articles about controversial topics such as dating, harassment, and sexuality (although these are typically prefaced with a "read at your own risk" statement emphasizing the mature nature of the content) suggests that tweens' concerns are being taken seriously. Further, the editor uses the space afforded by the editor's notes to support tweens in making appropriate decisions and to further their thinking about particular topics by raising questions. Similarly, the supervising adult in the after school gaming club monitored game play and player behavior. When Ulani reported a threatening situation, a supervising adult was present to support the tweens in formulating an appropriate response. The supervising adult also provided a link to parents, and, in this way, the incident generated constructive dialogue about appropriate and inappropriate behavior. Thus, while tweens may be capable of handling more than we often give them credit for, such incidents become teachable moments only when adults are present to play supportive and supervisory roles.

The findings presented in this paper constitute useful information for researchers, teachers, and parents faced with similar problematic situations. The incident we observed could serve as discussion material for "what if" scenarios in which students are asked to discuss their reactions and develop action plans. Parents could be informed about the various venues available to them to report problems experienced in a virtual world and to discuss with their children.

Our findings are limited to observations that took place within a particular community of tween players. We view this research as a first step toward a better understanding of the potential for engaging tweens in 
self-governance in virtual worlds. We do not know if tweens playing together online but not physically present in the same room would respond in the same way. We also do not know how much responsibility for governance tweens can handle before they become overwhelmed. As we attempt to learn more about tween governance in Whyville, we hope to explore potential interventions such as a more extensive peer-mentoring network in which more-experienced players help those with less experience navigate some of the social aspects of life in Whyville (Whyville already has y-mail helpers that assist with some of the technical aspects). At the same time, we hope that other researchers will continue to explore the issue of governance in adult, teen, and youth-focused virtual worlds, taking into account the specific needs and desires of each population.

\begin{tabular}{lll}
\multicolumn{4}{l}{ Appendix I: URLs of Websites Cited in the Article } \\
\hline Name & URL & Notes \\
\hline Barbie Girls & http://www.barbiegirls.com/ & \\
Club Penguin & http://www.clubpenguin.com/ & \\
Habbo Hotel & http://www.habbo.com/ & \\
MediaMoo & http://www.cc.gatech.edu/ asb & \\
& /mediamoo/ & \\
Neopets & http://www.neopets.com/ & Formerly \\
Net Nanny & http://www.netnanny.com/ \\
The Club & http://www.nick.com/club & Nicktropolis \\
& & \\
The Well & http://www.well.com/ \\
Webkinz & http://www.webkinz.com/ \\
Whyville & http://www.whyville.net & \\
\hline
\end{tabular}

\section{Acknowledgments}

A grant from the National Science Foundation (NSF0411814) supported the data collection for this case. A grant from the MacArthur Foundation to the first author supported the analysis and writing. The views expressed are those of the authors and do not necessarily represent the views of the National Science Foundation, MacArthur Foundation, the University of Pennsylvania, the University of California, Los Angeles, or Numedeon. Numedeon, Inc., the company that owns and hosts Whyville.net, has no control over the publication of the results. The authors have no financial interest in or any other official relationship with Numedeon, Inc. We appreciate Numedeon's willingness to cooperate in the research studies and to provide access to their log file data. Special thanks goes to Deborah Fields for her comments on earlier drafts of this article.

\section{References}

Bartle, Richard. 2003. Designing virtual worlds. Indianapolis, IN: New Riders.

Boellstorff, Thomas. 2008. Coming of age in Second Life: An anthropologist explores the virtually human. Princeton, NJ: Princeton University Press.

Bruckman, Amy, Pavel Curtis, Cliff Figallo, and Brenda Laurel. 1994. Approaches to managing deviant behavior in virtual communities. Paper presented at the Computer Human Interaction conference, Boston, MA. http://www.cc.gatech .edu/ asb/papers/deviance-chi94.txt (accessed December 17, 2010).

Cassell, Justine, and Mara Cramer. 2008. High tech or high risk: Moral panics about girls online. In Digital youth, innovation, and the unexpected, ed. T. McPherson, 53-76. Cambridge, MA: MIT Press.

Consalvo, Mia. 2007. Cheating: Gaining advantage in video games. Cambridge, MA: MIT Press.

Dibbell, Julian. 1998. My tiny life: Crime and passion in a virtual world. New York: Henry Holt and Company.

Federation of American Scientists. 2009. Virtual worlds almanac. http://vworld.fas.org/wiki/Main_Page (accessed May 18, 2009).

Fields Deborah A., and Yasmin B. Kafai. 2008. Knowing and throwing mudballs, hearts, pies, and flowers: A connective ethnography of gaming practices. In Proceedings of the Eighth International Conference of the Learning Sciences, ed. V. Jonker, A. Lazonder, and C. Hoadley. Utrecht: University of Utrecht.

Fields, Deborah A., and Yasmin B. Kafai. 2009. A connective ethnography of peer knowledge sharing and diffusion in a tween virtual world. International Journal of Computer Supported Collaborative Learning 4:47-68. http://dx.doi.org/10.1007/s11412-008-9057-1 (accessed December 22, 2010).

Fields, Deborah A., and Yasmin B. Kafai. Forthcoming. Navigating life as an avatar: The shifting identitiesin-practice of a girl player in a tween virtual world. In Technology, learning, and identity: Research on the development and exploration of selves in a digital world, ed. C. C. Ching and B. Foley. New York: Cambridge University Press.

Gee, James P. 2003. What video games have to teach us about learning and literacy. New York: Palgrave MacMillan.

Greenfield, Patricia. 2004. Developmental considerations for determining appropriate Internet use guidelines for children and adolescents. Journal of Applied Developmental Psychology 25:751-62. http://dx.doi.org/10.1016 /j.appdev.2004.09.008 (accessed December 22, 2010).

Kafai, Yasmin B. 2008. Gender play in a tween gaming club. In Beyond Barbie and Mortal Kombat: New perspectives on gender and gaming, ed. Yasmin B. Kafai, Carrie Heeter, Jill Denner, and Jennifer Sun, 111-24. Cambridge, MA: MIT Press.

Kafai, Yasmin B., and Deborah A. Fields. Forthcoming. Understanding player participation and practices in virtual worlds: A proposal for qualitative analyses of log file data. In Research methods in virtual worlds, ed. Douglas Thomas. Cambridge, MA: MIT Press. 
Keith, Susan, and Michelle E. Martin. 2005. Cyber-bullying: Creating a culture of respect in a cyberworld. Reclaiming Children and Youth 13 (4):224-28.

Lubeck, Sally. 1998. Is developmentally appropriate practice for everyone? Childhood Education 74 (5):283-92.

Pellegrini, Anthony D. 1995. A longitudinal study of boys' rough-and-tumble play and dominance during early adolescence. Journal of Applied Developmental Psychology 16: 77-93. http://dx.doi.org/10.1016/0193-3973(95)90017-9 (accessed December 22, 2010).

Provenzo, Eugene F., Jr. 1991. Video kids: Making sense of Nintendo. Cambridge, MA: Harvard University Press.

Roberto, Anthony J., Kellie E. Carlyle, Rick S. Zimmerman, Erin L. Abner, Pamela K. Cupp, and Gary L. Hansen. 2008. The short-term effects of a computer-based pregnancy, STD, and HIV prevention program. Communication Quarterly 56 (1):29-48. http://dx.doi.org/10.1080/ 01463370701839255 (accessed December 22, 2010).

Roberto, Anthony J., Rick S. Zimmerman, Kellie E. Carlyle, Erin L. Abner, Pamela K. Cupp, and Gary L. Hansen. 2007. The effects of a computer-based pregnancy, STD, and HIV prevention intervention: A nine-school trial. Health Communication 21 (2):115-24.
Rotundo, E. Anthony. 1998. Boy culture. The children's culture reader, ed. Henry Jenkins, 337-62. New York: NYU Press.

Salen, Katie, and Eric Zimmerman. 2004. Rules of play: Game design fundamentals. Cambridge, MA: MIT Press.

Steinkuehler, Constance. 2007. The mangle of play. Games and Culture 1 (3):1-14. http://dx.doi.org/10.1177/ 1555412006290440 (accessed December 22, 2010).

Stevens, Reed, Tom Satwicz, and Laurie McCarthy. 2008. In-game, in-room, in-world: Reconnecting video game play to the rest of kids' lives. In The ecology of games: Connecting youth, games, and learning, ed. Katie Salen, 41-66. Cambridge, MA: MIT Press.

Subrahmanyam, Kaveri, David Smahel, and Patricia Greenfield. 2006. Connecting developmental constructions to the Internet: Identity presentation and sexual exploration in online teen chat rooms. Developmental Psychology 42 (3):395-406. http://dx.doi.org/10.1037/0012 -1649.42.3.395 (accessed December 22, 2010).

Taylor, Tina L. 2006. Beyond management: Considering participatory design and governance in player culture. First Monday 7. http://firstmonday.org/htbin/cgiwrap/bin/ojs/index .php/fm/article/view/1611/1526 (accessed May 18, 2009).

Thorne, Barrie. 1993/1998. Gender play: Girls and boys in school. New Brunswick, NJ: Rutgers University Press. 